\title{
Investigation on low-cycle fatigue of aluminium alloy welded joints
}

\author{
S. Kilikevičius*, R. Česnavičius**, P. Krasauskas***, R. Dundulis****, \\ N. Sai. Madhusudanan****** \\ *Kaunas University of Technology, Studentu 56, 51424 Kaunas, Lithuania, E-mail: sigitas.kilikevicius@ktu.lt \\ **Kaunas University of Technology, Studentu 56, 51424 Kaunas, Lithuania, E-mail: ramunas.cesnavicius@ktu.lt \\ ***Kaunas University of Technology, Studentu 56, 51424 Kaunas, Lithuania, E-mail: povilas.krasauskas@ktu.lt \\ ****Kaunas University of Technology, Studentu 56, 51424 Kaunas, Lithuania, E-mail: romualdas.dundulis@ktu.lt \\ *****Kaunas University of Technology, Studentu 56, 51424 Kaunas, Lithuania, E-mail: madhusudanan.nagesh@ktu.edu \\ cross $^{\text {ref }}$ http://dx.doi.org/10.5755/j01.mech.22.5.15304
}

\section{Introduction}

The process of welding is a reliable, low-cost and convenient method for joining mechanical components in case a permanent joint is required. In conventional welding methods, a heat source is used or generated to melt the parent metal and the filler metal and diffuse them together. After diffusion, the joint is allowed to cool to form a permanent bond. During the process of cooling, metallurgical phenomenon takes place for example nucleation and crystallization of molten metal. The grain size formed and the type of phases generated affects the overall strength of the weld. Since the heat affected zone (HAZ) significantly decreases the strength of the weld, there is a need for other than conventional methods which would allow produce smaller HAZs. One of them is friction stir welding (FSW) considered as a non-traditional welding method. This method now is considered as one of the most advanced for aluminium alloys and is used in various fields of industry: aviation, train and marine building, chemical industry etc. to weld aluminium materials which are difficult to weld by other processes [1]. It has the benefits of operation and investment cost savings, weight reduction, high repeatability and consistence, low maintenance, better work environment and recyclability versus other conventional methods.

Welded joints are often used in structures influenced by high loads which are not often repeatable, therefore, the elastic-plastic strain may occur in the weld. Under cyclic elastic-plastic loading, after the cycle number of hundreds - thousands, the fatigue crack appears which commonly causes failures. This phenomenon is known as fatigue failure and is the most to investigate and understand before it happens. The problem of low-cycle fatigue remains still relevant, despite years of long-lasting investigations in this field.

Daunys et al. studied low-cycle fatigue properties under tension-compression and torsion for structural steels and their weld materials [2,3]. Low cycle fatigue properties of friction stir welded joints of a semi-solid processed AZ91D magnesium alloy was investigated by $\mathrm{Ni}$ et al. and it was found that a fatigue crack initiated basically from the pores at or near the specimen surface, and crack propagation was mainly characterized by fatigue striations along with the presence of secondary cracks [4]. Czechowski studied low-cycle fatigue of friction stir welded $\mathrm{Al}-\mathrm{Mg}$ alloys and compared them with joints welded by the metal inert gas (MIG) method [5]. It was found that the FSW welds have better mechanical properties and a higher fatigue life in comparison to the joints welded by the MIG method. Ceschini et al. studied the tensile and low-cycle fatigue behaviour of FSW joints of aluminium-based composites and presented cyclic stress response curves, which showed evidence of progressive hardening to failure of the FSW composite and a progressive softening of the base material. $[6,7]$. The influence of the FSW processing parameters on the low-cycle fatigue behaviour was investigated by Cavaliere et al. [8]. Numerical methods are being recently applied for investigations of crack propagation in friction stir welded joints $[9,10]$.

The literature overview showed that low-cycle fatigue curves are not obtained for many materials used in FSW and the cyclical stability properties of low-cycle fatigue of FSW joints are not investigated.

This paper presents an investigation on low-cycle fatigue of aluminium alloy AW 1050 welded joints welded by the FSW and Tungsten Inert Gas (TIG) methods along with a comparison to plain specimens. The cyclical behaviour properties and lifetime of these welded joints were studied under stress controlled unidirectional stress $(R=0)$ cyclic loading in order to compare the influence of the welding method on the durability of welded structures.

\section{Experimental setup}

Thin sheets of aluminium alloy AW 1050 were used for preparation of the specimens. Specimens of three types were produced: not welded (Fig. 1, a), FSW welded (Fig. 1, b) and TIG welded (Fig. 1, c).

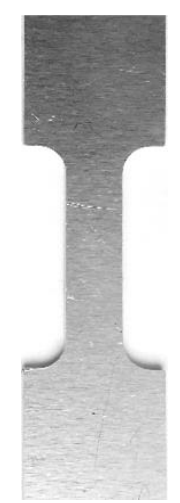

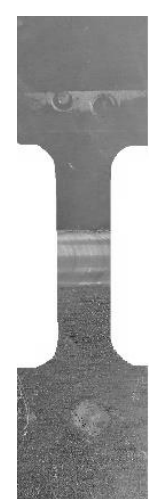

b



Fig. 1 Specimens for testing: (a) not welded; (b) FSW welded; (c) TIG welded 
The dimensions of the specimens used in the tests are presented in Fig. 2.

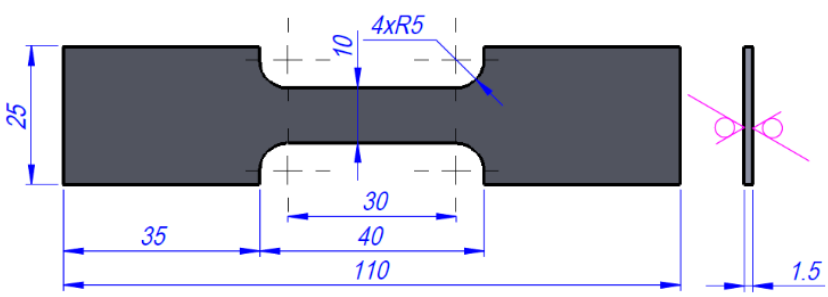

Fig. 2 Shape and dimension of a specimen for monotonous tension and low-cycle fatigue testing

The specimens for the investigation of the cyclical properties of FSW joints were manufactured welding two plates of $1.5 \mathrm{~mm}$ thickness using a standard square tip tool. The FSW was done at a feed rate of $100 \mathrm{~mm} / \mathrm{min}$ and a spindle rotation speed of $2000 \mathrm{rpm}$.

The specimens for the investigation of TIG welded joints were prepared joining two plates with closed square butt welds from both sides by using an MAL 4043 filler wire and an amperage of $65 \mathrm{~A}$. Finally, all the plates were cut to the required dimensions using the laser cutting method.

Monotonic tension tests and low-cycle fatigue tension-compression tests were carried out on a universal testing system "Instron ElectroPuls ${ }^{\mathrm{TM}} \mathrm{E} 10000$ " which has a linear (axial) static loading capacity up to $7 \mathrm{kN}$ and a dynamic loading capacity up to $10 \mathrm{kN}$.

With the process of experimentation, the data of engineering stress, engineering strain and some such quantities were recorded on a timely basis with the help of a computer connected to the machine.

The strain was calculated by measuring the change in the length of the specimen per unit of the true test length $L_{b}$ (deformation base), which was calculated using the following expression:

$$
L_{b}=L_{c}+2\left[0.005 t r-(0.025 t)^{2}\right]^{0.5},
$$

where $t$ is the specimen thickness, $r$ is the fillet radius and $L_{c}$ is the working length of the specimen.

The obtained value of the true test length was $L_{b}=30.379 \mathrm{~mm}$.

\section{Experimental analysis}

\subsection{Monotonic tension stress-strain behaviour}

During the experiments of monotonous loading, the monotonous stress-strain curves were obtained. The monotonic tensile test was conducted on each type of specimens (not welded, FSW welded and TIG welded). The curves of the monotonous tension (Fig. 3) in the coordinates $\sigma_{i}-e_{i}$ were obtained applying the equalities:

$$
\sigma_{i}=\sigma_{1} ; e_{i}=e_{1}
$$

The determined mechanical properties of the aluminium alloy and welded joints are presented in Table 1.

As it is seen from Table 1, the ultimate tensile strength of the AW 1050 not welded specimens is 1.2 and

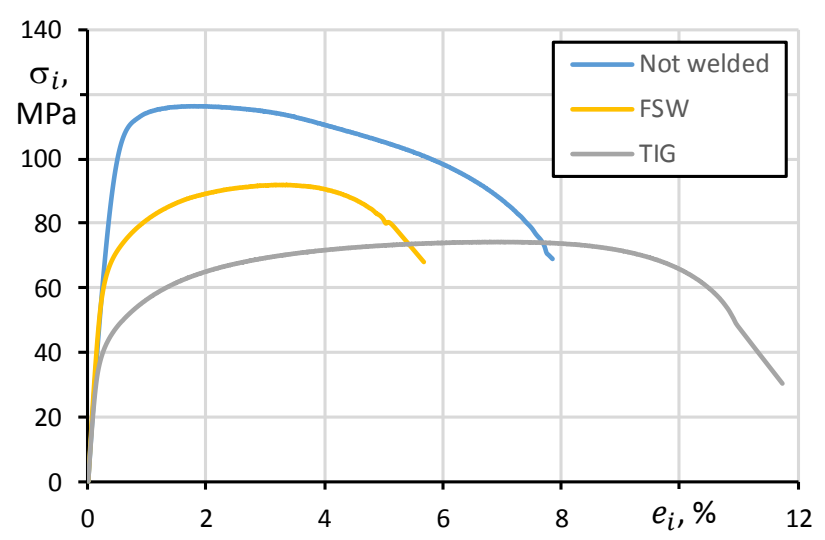

Fig. 3 Monotonic tensile stress-strain curves of AW 1050 not welded, FSW welded and TIG welded specimens

Table 1

Mechanical properties of aluminium AW 1050 alloy and welded joints

\begin{tabular}{|l|c|c|c|}
\hline \multirow{2}{*}{ Type } & $\sigma_{p r}$ & $\sigma_{u}$ & $e_{p r}$ \\
\cline { 2 - 4 } & \multicolumn{2}{|c|}{$\mathrm{MPa}$} & $\%$ \\
\hline Not welded & 77 & 116 & 0.330 \\
\hline FSW & 55 & 92 & 0.198 \\
\hline TIG & 25 & 74 & 0.202 \\
\hline
\end{tabular}

1.6 times higher compared to the FSW and TIG welded specimens, respectively. Whereas, among the welds, the FSW welded joints possess better mechanical properties, compared to the TIG welded joints. This can be explained by the fact that FSW is a solid state welding process, thus, the base metal is not melted completely to the melting point but is just softened and aggregated by the square tip tool with increase in movement of the rotating spindle along the weld seam, therefore, there is a significant smaller HAZ generated in compared to TIG welding. It means that in the TIG welding process, a larger HAZ occurs and formation of different grain structure along the weld where the mechanical properties is significantly reduced.

\subsection{Low-cycle stress-strain behaviour}

The specimens were subjected to low-cycle unidirectional $(R=0)$ stress controlled loading within the intervals of the stress amplitudes shown in Table 2.

Table 2

Intervals of normalized stress amplitude for low-cycle stress controlled tests

\begin{tabular}{|c|c|}
\hline Type & Normalised loading stress amplitude $\bar{\sigma}_{0}, \mathrm{MPa}$ \\
\hline Not welded & $1.33-1.88$ \\
\hline FSW & $1.32-1.50$ \\
\hline TIG & $1.32-1.38$ \\
\hline
\end{tabular}

The normalized stress $\left(\bar{\sigma}_{0}\right)$ amplitudes are used as the calculations are to be strictly depend on the material properties of the specimens. Under stress controlled cyclic loading the variation of the normalized semicycle plastic strain hysteresis loop width $\left(\bar{\delta}_{k}\right)$ with the increase in number of semicycles $k$, determines the cyclic stability of the material (in this case, welded and not welded specimens). The 
normalized stress amplitude and the normalized semicycle hysteresis loop width are expressed as follow:

$$
\bar{\sigma}_{0}=\frac{\sigma_{0}}{\sigma_{p r}} ; \bar{\delta}_{k}=\frac{\delta_{k}}{e_{p r}},
$$

where $\sigma_{0}$ is the loading stress amplitude, $\delta_{k}$ is the semicycle plastic strain hysteresis loop width, $\sigma_{p r}$ and $e_{p r}$ are the proportional stress and strain limits, respectively, $k=2 \mathrm{~N}$ and $N$ is the number of cycles.

The proportional stress and strain limits considered for studying the variation of semicycle hysteresis loop width variation for each type of specimen depending on the material properties. The plots of variation of semicycle hysteresis loop width with respect to number of loading cycles for the AW 1050 not welded, FSW and TIG welded specimens are presented in Fig. 4, 5 and 6, respectively.

From Fig. 4, 5 and 6 it is seen that $\bar{\delta}_{k}$ remains constant during low-cycle uniaxial stress controlled $(R=0)$ loading.
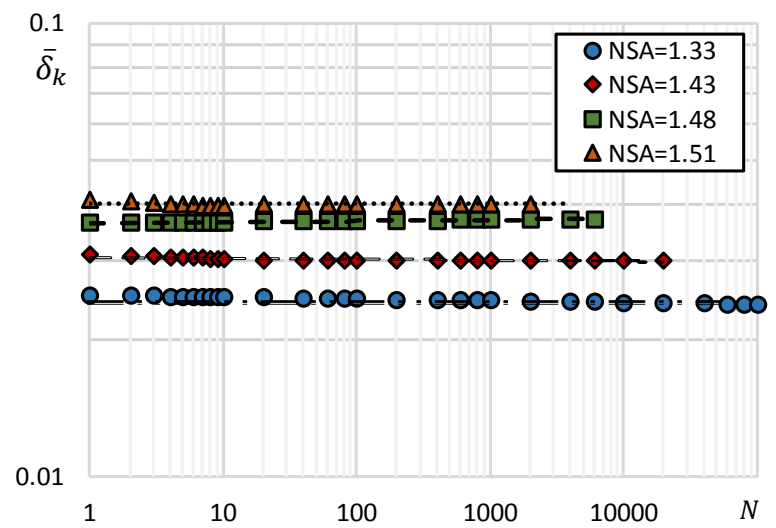

Fig. 4 Normalized semicycle hysteresis loop width $\bar{\delta}_{k}$ vs. loading cycles $N$ during unidirectional stress controlled cycle $(R=0)$ loading for the AW 1050 not welded specimens (the label NSA stands for normalized stress amplitude)

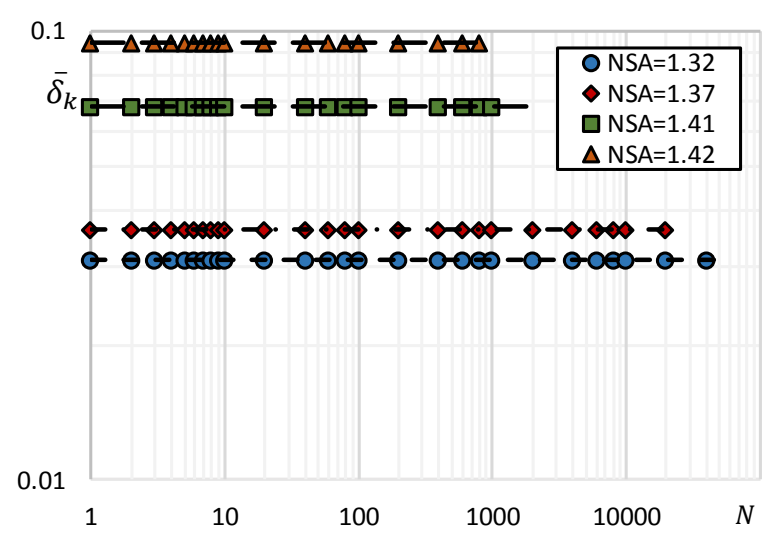

Fig. 5 Normalized semicycle hysteresis loop width $\bar{\delta}_{k}$ vs. loading cycles $N$ during unidirectional stress controlled cycle $(R=0)$ loading for the AW $1050 \mathrm{FSW}$ specimens

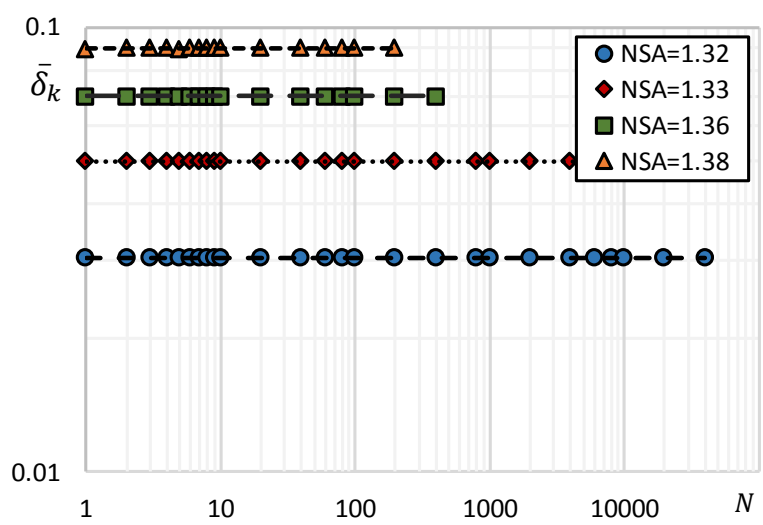

Fig. 6 Normalized semicycle hysteresis loop width $\bar{\delta}_{k}$ vs. loading cycles $N$ during unidirectional stress controlled cycle $(R=0)$ loading for the AW 1050 TIG welded specimens

Therefore, it could be concluded that the material AW 1050 is cyclically stable. The same cyclical properties remain for AW 1050 aluminium alloy FSW and TIG welded joints.

It was noticed that the semicycle plastic strain hysteresis loop width $\bar{\delta}_{k}$ variation is larger in even numbered semicycles and smaller in odd numbered semicycles $\left(\bar{\delta}_{\text {even }}>\bar{\delta}_{\text {odd }}\right)$, therefore the semicycle plastic strain hysteresis loop width $\bar{\delta}_{k}$ dependence on the number of loading semicycles $k$ can be expressed as follows [11]:

$$
\bar{\delta}_{k}=A_{1,2}\left(\bar{e}_{0}-\frac{\bar{S}_{T}}{2}\right) k^{\alpha},
$$

where $\bar{e}_{0}$ is the normalized initial plastic strain, $\bar{S}_{T}$ is the cyclic proportional limit, $A_{1}, A_{2}$ and $\alpha$ are the cyclic characteristics of the material in even and odd semicycles, respectively.

The accumulated plastic strain after loading semicycles $k$, can be expressed as follows [11]:

$$
\bar{e}_{p k}=\bar{e}_{0}-\bar{\sigma}_{0}+\sum_{1}^{k}(-1)^{k} \bar{\delta}_{k} .
$$

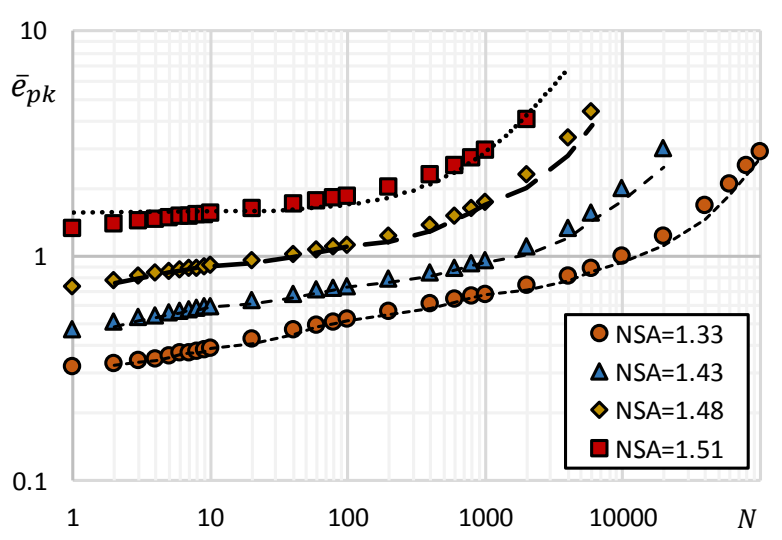

Fig. 7 Accumulated plastic strain $\bar{e}_{p k}$ vs. loading cycles $N$ for the AW 1050 not welded specimens 
It was observed that the AW 1050 not welded, FSW welded and TIG welded specimens are accumulating plastic strain during unidirectional stress controlled cycle $(R=0)$ loading. Fig. 7, 8 and 9 represent the dependence of the accumulated plastic strain on the number of cycles for the AW 1050 not welded, FSW welded and TIG welded specimens, respectively.

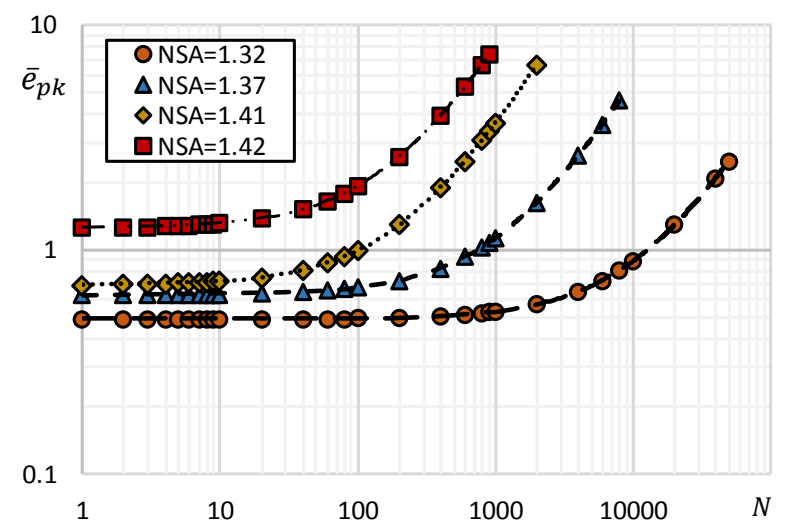

Fig. 8 Accumulated plastic strain $\bar{e}_{p k}$ vs. loading cycles $N$ for the AW $1050 \mathrm{FSW}$ specimens



Fig. 9 Accumulated plastic strain $\bar{e}_{p k}$ vs. loading cycles $N$ for the AW 1050 TIG welded specimens

From Fig. 7, 8 and 9 it can be seen that AW 1050 aluminium alloy as well as FSW and TIG welded joints from the same aluminium alloy are accumulating plastic strain. The accumulation of plastic strain was more significant for the welded specimens in compare of the AW 1050 not welded ones. The most intense accumulation was observed in the TIG welded specimens.

\subsection{Low-cycle fatigue analysis}

The number of cycles at which the failure of the specimens took place is less than $10^{5}$ cycles so, the type of loading falls under the category of low-cycle fatigue. The low-cycle fatigue test carried out is stress controlled lowcycle fatigue and can be approximated by the stress life curve [12]:

$$
\bar{\sigma}_{i}=\bar{S}_{f}^{\prime}\left(N_{f}\right)^{b}
$$

where $\bar{\sigma}_{i}$ is the normalized stress intensity amplitude, $\bar{S}_{f}^{\prime}$ is fatigue strength coefficient and is approximately equal to the monotonic true fracture stress $S_{f}^{\prime}, N_{f}$ is the number of cycles to failure, $b$ is the fatigue strength exponent. A smaller value of $b$ results in a longer fatigue life of the component.

Fig. 10, shows the $\bar{\sigma}_{i}-N$ curves obtained for the AW 1050 not welded, FSW and TIG welded specimens, respectively.

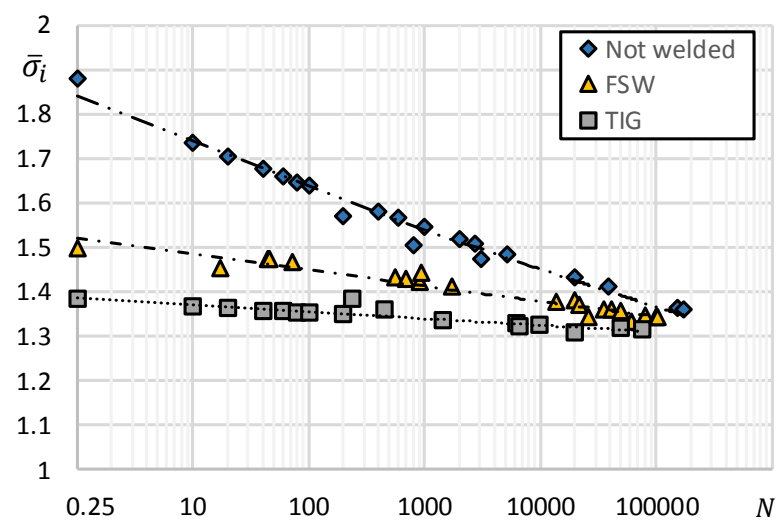

Fig. $10 \bar{\sigma}_{i}-N$ curves of the AW 1050 not welded, FSW and TIG welded specimens

The fatigue properties of the specimens obtained are presented in Table 3.

Table 3

Coefficients of Eq. 6

\begin{tabular}{|l|c|c|}
\hline \multicolumn{1}{|c|}{ Type } & $\bar{S}_{f}^{\prime}$ & $b$ \\
\hline Not welded & 1.84 & 0.026 \\
\hline FSW & 1.52 & 0.011 \\
\hline TIG & 1.39 & 0.005 \\
\hline
\end{tabular}

From the above obtained data it can be concluded that the AW 1050 not welded specimens have the highest fatigue life as it has the lowest $b$ value. Among the welded joints, the FSW ones have a better fatigue life.

\section{Conclusions}

Monotonic tension and stress controlled unidirectional stress $(R=0)$ loading experiments were performed on aluminium AW 1050 alloy not welded, FSW and TIG welded specimens in order to compare the influence of the welding method on the durability of welded structures.

It was found that among the welded joints, the FSW joints have a higher weld strength in compare to the TIG welded joints under both the monotonic tension and cyclic loading conditions.

The results of the low-cyclic loading tests showed that the material AW 1050 is cyclically stable as the semicycle hysteresis loop width remains constant with increase in number of cycles. The same cyclical properties remain for AW 1050 aluminium alloy FSW and TIG welded joints.

It was observed that AW 1050 aluminium alloy as well as FSW and TIG welded joints from the same alumin- 
ium alloy are accumulating plastic strain in tension direction. The accumulation of plastic strain was more significant for the welded specimens in compare of the AW 1050 not welded specimens. The most intense accumulation was observed in the TIG welded specimens.

The stress controlled low-cycle fatigue testing enabled to conclude the AW 1050 not welded specimens have the highest fatigue life as the fatigue strength exponent $b$ has the lowest value. Among the welded joints, the FSW ones have a better fatigue life.

\section{References}

1. Smith, C.B.; Hinrichs, J.F.; Ruehl, P.C. 2004 . Friction Stir and Friction Stir Spot Welding-Lean, Mean and Green. In Detroit American Welding Society Sheet Metal Conference.

2. Daunys, M.; Šniuolis, R.; Stulpinaitė, A. 2012. Evaluation of cyclic instability by mechanical characteristics for structural materials, Mechanika 18(3): 280-284. http://dx.doi.org/10.5755/j01.mech.18.3.1887.

3. Daunys, M.; Česnavičius, R. 2009. Low-cycle stress strain curves and fatigue under tension-compression and torsion, Mechanika 6(80): 5-11.

4. Ni, D.R.; Chen, D.L.; Yang, J.; Ma, Z.Y. 2014. Low cycle fatigue properties of friction stir welded joints of a semi-solid processed AZ91D magnesium alloy, Materials \& Design 56: 1-8. http://dx.doi.org/10.1016/j.matdes.2013.10.081.

5. Czechowski, M. 2005. Low-cycle fatigue of friction stir welded $\mathrm{Al}-\mathrm{Mg}$ alloys, Journal of Materials Processing Technology 164: 1001-1006. http://dx.doi.org/10.1016/j.jmatprotec.2005.02.078.

6. Ceschini, L.; Boromei, I.; Minak, G.; Morri, A.; Tarterini, F. 2007. Microstructure, tensile and fatigue properties of $\mathrm{AA} 6061 / 20 \mathrm{vol} . \% \mathrm{Al}_{2} \mathrm{O}_{3 \mathrm{p}}$ friction stir welded joints, Composites Part A: Applied Science and Manufacturing 38(4): 1200-1210. http://dx.doi.org/10.1016/j.compositesa.2006.06.009.

7. Ceschini, L.; Boromei, I.; Minak, G.; Morri, A.; Tarterini, F. 2007. Effect of friction stir welding on microstructure, tensile and fatigue properties of the AA7005/10vol. $\% \mathrm{Al}_{2} \mathrm{O}_{3 \mathrm{p}}$ composite, Composites Science and Technology 67(3): 605-615.

http://dx.doi.org/10.1016/j.compscitech.2006.07.029.

8. Cavaliere, P.; Squillace, A.; Panella, F. 2008. Effect of welding parameters on mechanical and microstructural properties of AA6082 joints produced by friction stir welding, Journal of Materials Processing Technology 200(1): 364-372.

http://dx.doi.org/10.1016/j.jmatprotec.2006.06.015.
9. Đurđević, A.; Živojinović, D.; Grbović, A.; Sedmak, A.; Rakin, M.; Dascau, H.; Kirin, S. 2015. Numerical simulation of fatigue crack propagation in friction stir welded joint made of Al 2024-T351 alloy, Engineering Failure Analysis 58: 477-484. http://dx.doi.org/10.1016/j.engfailanal.2015.08.028.

10. Carlone, P.; Citarella, R.; Sonne, M.R.; Hattel, J.H. 2016. Multiple crack growth prediction in AA2024-T3 friction stir welded joints, including manufacturing effects, International Journal of Fatigue 90: 69-77. http://dx.doi.org/10.1016/j.ijfatigue.2016.04.004.

11. Daunys, M. Cycle Strength and Durability of Structures. -Kaunas: Technologija, 2005. -286p. (in Lithuanian).

12. Bannantine, J. 1990. Fundamentals of metal fatigue analysis. Prentice Hall, 273 p.

S. Kilikevičius, R. Česnavičius, P. Krasauskas,

R. Dundulis, N. Sai Madhusudanan

\section{INVESTIGATION ON LOW-CYCLE FATIGUE OF ALUMINIUM ALLOY WELDED JOINTS}

S u m m a r y

In this paper, the low-cycle unidirectional stress controlled $(R=0)$ loading experiments were carried out on AW 1050 aluminium alloy friction stir welded (FSW) and tungsten inert gas welded (TIG) specimens in order to compare the influence of the welding method on the durability of welded structures.

It was found that, under stress controlled unidirectional stress $(R=0)$ loading, the material AW 1050 is cyclically stable as the semicycle hysteresis loop width remains constant with increase in number of cycles. The same cyclical properties remain for AW 1050 aluminium alloy FSW and TIG welded joints. All the specimens demonstrated a tendency to accumulate the plastic strain. The stress controlled low-cycle fatigue testing enabled to conclude that the AW 1050 not welded specimens have the highest fatigue life. Among the welded joints, the FSW ones have a better fatigue life.

Keywords: FSW, TIG, welded joints, hysteresis loop, accumulated plastic strain, stress control, low-cycle fatigue.

Received June 16, 2016

Accepted September 28, 2016 